Article

\title{
Pharmacokinetics and Metabolism of Acetyl Triethyl Citrate, a Water-Soluble Plasticizer for Pharmaceutical Polymers in Rats
}

\author{
Hyeon Kim ${ }^{1,+}$, Young Seok $\mathrm{Ji}^{1,+}$, Shaheed Ur Rehman ${ }^{2}$, Min Sun Choi ${ }^{1}$, Myung Chan Gye ${ }^{3, *}$ \\ and Hye Hyun Yoo ${ }^{1, *(1)}$ \\ 1 Institute of Pharmaceutical Science and Technology and College of Pharmacy, Hanyang University, Ansan, \\ Gyeonggi-do 15588, Korea; kimhyeon2000@nate.com (H.K.); wldudtjr23@hanyang.ac.kr (Y.S.J.); \\ chm2456@hanyang.ac.kr (M.S.C.) \\ 2 Department of Pharmacy, COMSATS, Institute of Information Technology, Lahore, Punjab 54000, Pakistan; \\ dr.shaheedmarwat@yahoo.com \\ 3 Department of Life Science, Institute of Natural Sciences, Hanyang Uuiversity, Seoul 04763, Korea \\ * Correspondence: mcgye@hanyang.ac.kr (M.C.G.); yoohh@hanyang.ac.kr (H.H.Y.); \\ Tel.: +82-10-400-5804 (H.H.Y.) \\ + These authors contributed equally to this work.
}

Received: 7 March 2019; Accepted: 2 April 2019; Published: 3 April 2019

\begin{abstract}
Acetyl triethyl citrate (ATEC) is a water-soluble plasticizer used in pharmaceutical plasticized polymers. In this study, the pharmacokinetics and metabolism of ATEC were investigated using liquid chromatography-tandem mass spectrometry (LC-MS/MS) in rats. Plasma protein precipitation with methanol was used for sample preparation. For chromatographic separation, a C18 column was used. The mobile phases consisted of $0.1 \%$ formic acid and $90 \%$ acetonitrile, and gradient elution was used. The following precursor-product ion pairs were selected for reaction monitoring analysis: $319.1 \mathrm{~m} / \mathrm{z} \rightarrow 157 \mathrm{~m} / \mathrm{z}$ for ATEC and $361.2 \mathrm{~m} / \mathrm{z} \rightarrow 185.1 \mathrm{~m} / \mathrm{z}$ for tributyl citrate (internal standard) in positive ion mode. The LC-MS/MS method was fully validated and successfully applied to a pharmacokinetic study of ATEC in rats. The pharmacokinetic study showed that the volume of distribution and mean residence time of ATEC were higher after oral administration than after intravenous administration, pointing to extensive first-pass metabolism and distribution in tissue. In addition, the plasma concentration profile of the postulated metabolites of ATEC was investigated in plasma, urine, and feces. The resulting data indicated that ATEC was extensively metabolized and excreted mainly as metabolites rather than as the parent form. The developed analytical method and the data on the pharmacokinetics and metabolism of ATEC may be useful for understanding the safety and toxicity of ATEC.
\end{abstract}

Keywords: acetyl triethyl citrate; plasticizer; pharmaceutical polymers; pharmacokinetics; metabolism

\section{Introduction}

Plasticized polymers are substantial in pharmaceutical technology. For example, they can be used as coating materials of dosage forms, free membranes of pharmaceutical films, polymeric membranes of transdermal system, matrix systems for extended release formulations, or microparticles [1]. Plasticizers play important roles in diverse pharmaceutical plasticized polymers by improving their flexibility and processability [1].

Acetyl triethyl citrate (ATEC) is one of the plasticizers used in pharmaceutical plasticized polymers [1]. It is an aliphatic ester of citric acid which is a clear oily liquid with essentially no odor. In pharmaceutical polymers, ATEC is used as a hydrophilic plasticizer in the coating of press-coated 
tablets that are composed of hydroxypropyl methylcellulose acetate succinate or enteric polymer films consisting of polymethacrylic acid methylmethacrylate [1-5]. ATEC is also used in protein films composed of whey protein or sunflower protein for buccal and sublingual films or particulate systems [1]. Given the uses of ATEC in various pharmaceutical formulations, the safety and toxicity of ATEC in the body should be thoroughly evaluated.

There have been some toxicology reports on ATEC. In terms of acute oral toxicity, the LD50 for ATEC was reported to be approximately $7 \mathrm{~mL} / \mathrm{kg}$ in rats and cats [6]. ATEC doses of $6-12 \mathrm{~mL} / \mathrm{kg}$ caused progressive lowering of the blood pressure [7]. In a study of short-term oral toxicity, feeding rats a diet containing 1-4 g/kg of ATEC for 6 weeks did not affect growth or induce toxicity [6]. The same study reported no adverse effects of ATEC on blood cells [6]. In the developmental toxicity test with Xenopus laevis embryos, the $96 \mathrm{~h}$ EC50 for malformation of ATEC was $413.8 \mathrm{mg} / \mathrm{L}$, and the $96 \mathrm{~h}$ lowest observed effective concentration for malformation of embryos was $363.5 \mathrm{mg} / \mathrm{L}$ [8]. These results indicate that the teratogenic potential of ATEC would be negligible, and its developmental toxicity may also be quite low. In Hershberger assays, ATEC did not show any significant androgenic or antiandrogenic activities [9]. Another study also indicated that ATEC has no effects on estrogen or antiestrogen activity or steroidogenesis. These reports suggest that ATEC may not have endocrine-disrupting activities [10]. Therefore, ATEC is considered relatively safe on the basis of the toxicological data published thus far.

However, concerns have been raised about potential blood pressure lowering effects of ATEC [7]. In addition, acetyl tributyl citrate (ATBC), which is structurally similar to ATEC, was shown to induce intestinal cytochrome P450 3A4 and affect female reproduction at a low dose [11]. Therefore, the safety of ATEC should be further investigated, and human exposure to ATEC needs to be monitored. However, the information on the pharmacokinetics of ATEC is still limited.

Analytical methods for ATEC include the use of infrared spectroscopy, nuclear magnetic resonance spectroscopy [12], and mass spectroscopy [13]. Thin-layer chromatography [14], gas chromatography [15,16], and high-performance liquid chromatography [17] have also been used for ATEC analysis. However, no studies have reported the use of liquid chromatography-tandem mass spectrometry (LC-MS/MS) for ATEC analysis. Furthermore, at present, there are no analytical methods for the determination of ATEC in biological samples.

In this study, we developed a bioanalytical method for the determination of ATEC in rat plasma using LC-MS/MS. On the basis of the developed method, we investigated the pharmacokinetic properties of ATEC in rats.

\section{Materials and Methods}

\subsection{Chemicals and Materials}

Acetyl triethyl citrate (ATEC, $>98 \%$ ), tributyl citrate (TBC, internal standard), and phenylmethylsulphonyl fluoride (PMSF) were purchased from Sigma-Aldrich (St. louis, MO, USA). HPLC-grade methanol (MeOH) was purchased from J.T. Baker (Phillipsburg, NJ, USA). Water was prepared using a Milli-Q purification system (Millipore, Bedford, MA, USA). Blank plasma was collected in a heparin tube from Male Sprague-Dawley rats. All other chemicals and solvents were of analytical grade.

\subsection{Preparation of Calibration and Quality Control (QC) Standards}

A stock solution of ATEC was prepared to yield a concentration of $5 \mathrm{mg} / \mathrm{mL}$ in $100 \%$ acetonitrile (ACN). The solution was stored at $-20{ }^{\circ} \mathrm{C}$ and brought back to normal room temperature before use. Working standard solutions were prepared by diluting the ATEC stock solution with $100 \%$ of ACN to final concentrations ranging from $0.1 \mu \mathrm{g} / \mathrm{mL}$ to $20 \mu \mathrm{g} / \mathrm{mL}$. A stock solution $(5 \mathrm{mg} / \mathrm{mL})$ of internal standard (IS) TBC was prepared in $100 \% \mathrm{ACN}$ and further diluted to a concentration of $100 \mathrm{ng} / \mathrm{mL}$ in the ACN. Blank rat plasma $(90 \mu \mathrm{L})$ was treated with $2.5 \mu \mathrm{L}$ of $1 \mathrm{M}$ PMSF, and the working standard solutions $(10 \mu \mathrm{L})$ were added to yield calibration standards of 10, 50, 100, 200, 500, 1000, and 
$2000 \mathrm{ng} / \mathrm{mL}$. QC samples were prepared in the same way as the calibration standards, having final concentrations of 10, 30, 300, and $1600 \mathrm{ng} / \mathrm{mL}$. The QC samples and calibration standards were kept frozen $\left(-20^{\circ} \mathrm{C}\right)$ until use. For protein precipitation, three volumes of the IS solution were added to calibration standards and QC samples, vortexed for 30 secs, and then centrifuged for $5 \mathrm{~min}$ at $10,000 \times g$ and $4{ }^{\circ} \mathrm{C}$. The supernatant was taken for LC-MS/MS analysis.

\subsection{Validation of the Analytical Method}

To determine the specificity of the assay, chromatograms of blank and standard-spiked plasma samples were compared and evaluated using six different batches of blank plasma. Calibration curves were constructed by plotting the ratios of the peak area from the analyte to that from the IS versus the analyte concentrations. The calibration curve was calculated by linear least-squares regression. The lower limit of quantification (LLOQ) was defined as the lowest concentration with a relative standard deviation (RSD) $<20 \%$ and with accuracy of $80-120 \%$. The precision and accuracy of the method were evaluated by repeated analyses of QC samples ( $n=5$ for intra-day and $n=3$ for inter-day) at concentrations of 10,30,300, and $1600 \mathrm{ng} / \mathrm{mL}$. Matrix effects were evaluated by comparing the peak area of the post-spiked extracted sample with that acquired using a neat solution, and the extraction recovery was measured by comparing the peak area of the pre-spiked extracted sample with that of the post-spiked extracted sample. To determine process efficiency, the peak area in the neat solution was compared with that in the pre-spiked extracted sample. The spiked extracted samples were prepared using pooled blank plasma from six different batches. Bench-top, freeze-and-thaw, long-term, and postpreparative stability studies were also performed to evaluate the stability of ATEC. The methods used in the validation procedures were based on the "Guidance for Industry: Bioanalytical Method Validation" [18].

\subsection{Pharmacokinetics Study in Rats}

Male Sprague-Dawley rats aged 8 weeks (weight, approximately 250-290 g) were purchased from Orient Bio (Seongnam, Korea) and housed in a temperature- $\left(23 \pm 3{ }^{\circ} \mathrm{C}\right)$ and moisture-controlled ( $55 \pm 15 \%$ relative humidity) room under a $12 \mathrm{~h}$ light-dark cycle, with access to food and water ad libitum. The rats fasted for $12 \mathrm{~h}$ before treatment and had free access to water. The rats were anesthetized with Zoletil 50 (Virbac, Carros, France) and Rompun ${ }^{\circledR}$ (Bayer, Leverkusen, Germany), and a polyethylene tube was surgically implanted into the carotid artery one day before the pharmacokinetic study. The cannulae were fixed to the head and neck, and the rats were allowed to move freely during the experiment. Dosing solutions were prepared in 30\% poly-ethylene glycol (PEG) at a concentration of $10 \mathrm{mg} / \mathrm{mL}$ for intravenous (i.v.) administration and $500 \mathrm{mg} / \mathrm{mL}$ for oral (p.o.) administration. The rats were administered ATEC intravenously $(10 \mathrm{mg} / \mathrm{kg})$ and orally $(500 \mathrm{mg} / \mathrm{kg})$. Blood samples $(200 \mu \mathrm{L})$ were collected from the carotid artery in tubes containing $1 \mu \mathrm{L}$ of heparin (5000 IU) and $5 \mu \mathrm{L}$ of an esterase inhibitor, PMSF (1M). The collection time points were $1 \mathrm{~min}, 2 \mathrm{~min}, 5 \mathrm{~min}, 10 \mathrm{~min}, 15 \mathrm{~min}$, $30 \mathrm{~min}, 1 \mathrm{~h}, 2 \mathrm{~h}, 4 \mathrm{~h}, 6 \mathrm{~h}, 10 \mathrm{~h}$, and $24 \mathrm{~h}$ after the i.v. injection and $5 \mathrm{~min}, 15 \mathrm{~min}, 30 \mathrm{~m}, 45 \mathrm{~min}, 1 \mathrm{~h}$, $2 \mathrm{~h}, 4 \mathrm{~h}, 6 \mathrm{~h}, 8 \mathrm{~h}, 10 \mathrm{~h}, 24 \mathrm{~h}$, and $36 \mathrm{~h}$ after p.o. administration. The collected blood samples were centrifuged at $10,000 \times g$ and $4{ }^{\circ} \mathrm{C}$ for $5 \mathrm{~min}$, and the supernatant plasma was collected.

To determine the metabolic profile of ATEC, the rats were placed in metabolic cages for 5 days after oral dosing $(500 \mathrm{mg} / \mathrm{kg})$. Urine and feces were collected $10 \mathrm{~h}, 1$ day, 2 day, 3 day, 4 day, and 4.3 day after oral administration. The collected samples were kept frozen at $-20{ }^{\circ} \mathrm{C}$ until use. All animal procedures were approved by the Institutional Animal Care and Use Committee of Hanyang University (2016-0235A).

\subsection{Sample Preparation}

The plasma and urine $(50 \mu \mathrm{L})$ samples were placed in separate $1.5 \mathrm{~mL}$ tubes and treated with $150 \mu \mathrm{L}$ IS $(100 \mathrm{ng} / \mathrm{mL}$ of $\mathrm{TBC}$ in $\mathrm{MeOH})$ for protein precipitation. The feces were homogenized with three volumes of $\mathrm{ACN}$ and centrifuged at $2000 \times g$ for $5 \mathrm{~min}$. The supernatant $(100 \mu \mathrm{L})$ was 
transferred to a tube, and $100 \mu \mathrm{L}$ of IS was added. The tubes were vortex-mixed and centrifuged at $10,000 \times \mathrm{g}$ and $4{ }^{\circ} \mathrm{C}$ for $5 \mathrm{~min}$. The supernatant was placed in a HPLC vial for LC-MS/MS or liquid chromatography-quadrupole time-of-flight-mass spectrometry (LC-QTOF-MS) analysis.

\subsection{Pharmacokinetics Analysis}

The pharmacokinetic parameters of the rat plasma samples were determined using the Phoenix WinNonlin Enterprise Program, v5.3 (Pharsight Inc., St. Louis, MO, USA) using a noncompartmental statistical model. The maximum plasma concentration $\left(C_{\max }\right)$ and the time to reach the $C_{\max }$ were obtained directly from the experimental data. The elimination half-life $\left(t_{1 / 2}\right)$ was calculated as $0.693 / \lambda z$, where $\lambda z$ is the elimination rate constant calculated from the terminal linear portion of the logged plasma concentration-time curve. To determine absolute bioavailability, the plasma drug concentration versus time plot for the drug dose after both i.v. and p.o. administrations was calculated from the experimented AUC values. The initial concentration in the i.v. administration, distribution volume based on the terminal phase $(\mathrm{Vz})$, and total body clearance were obtained from the experimental data, processed by WinNonlin (ver. 5.3) software.

\subsection{Metabolic Stability Assay}

ATEC was incubated with $\mathrm{pH} 7.4$ phosphate buffered saline at $37^{\circ} \mathrm{C}$ for $0,5,15,30,60$, and $120 \mathrm{~min}$; with rat plasma at $37^{\circ} \mathrm{C}$ for $0,5,15,30$, and $60 \mathrm{~min}$; and with rat liver microsomes at $37^{\circ} \mathrm{C}$ for $0,1,5$, 15,30 , and $60 \mathrm{~min}$. The detailed procedures have been described elsewhere $[19,20]$. After incubation, the sample was prepared as described in Section 2.5.

\section{8. $L C-M S / M S$}

An Agilent 1260 infinity HPLC system coupled with a 6460-triple quadrupole mass spectrometer (Agilent Technologies, Santa Clara, CA, USA) and an electrospray ionization source was used for quantitative analysis of the analytes. For chromatographic separation, a Phenomenex Kinetex C18 $(2.1 \mathrm{~mm} \times 50 \mathrm{~mm}, 2.1 \mu \mathrm{m})$ column with a thermostatically controlled column temperature at $30^{\circ} \mathrm{C}$ was used. The mobile phases consisted of $0.1 \%$ formic acid in DW (solvent A) and $0.1 \%$ formic acid in $90 \% \mathrm{ACN}$ (solvent $\mathrm{B}$ ), with a gradient elution at a flow rate of $0.3 \mathrm{~mL} / \mathrm{min}$. The gradient elution was initiated with $10 \%$ of mobile phase B, increased to $100 \%$ of B for $0.6 \mathrm{~min}$, and held for $2 \mathrm{~min}$, followed by re-equilibration to the initial condition for $4 \mathrm{~min}$. The total run time was $6 \mathrm{~min}$, and the injection volume was $5 \mu \mathrm{L}$. For selected reaction monitoring analyses, the following precursor-product ion pairs were used: $319.1 \mathrm{~m} / \mathrm{z} \rightarrow 157 \mathrm{~m} / \mathrm{z}$ for ATEC and $361.2 \mathrm{~m} / \mathrm{z} \rightarrow 185.1 \mathrm{~m} / \mathrm{z}$ for the IS in the positive ion mode. The fragmentor voltages were $70 \mathrm{~V}$ and $104 \mathrm{~V}$, and the collision energies were $10 \mathrm{~V}$ and $12 \mathrm{~V}$ for ATEC and IS, respectively. The product ion spectra of ATEC and TBC and their chemical structures are presented in Figure 1. 
(A) $\times 10^{3}$ +ESI Product Ion:2 (rt: 0.106-0.236 min, 5 scans) Frag=100.0V CF=0.000 DF=0.000 CID@7.0..

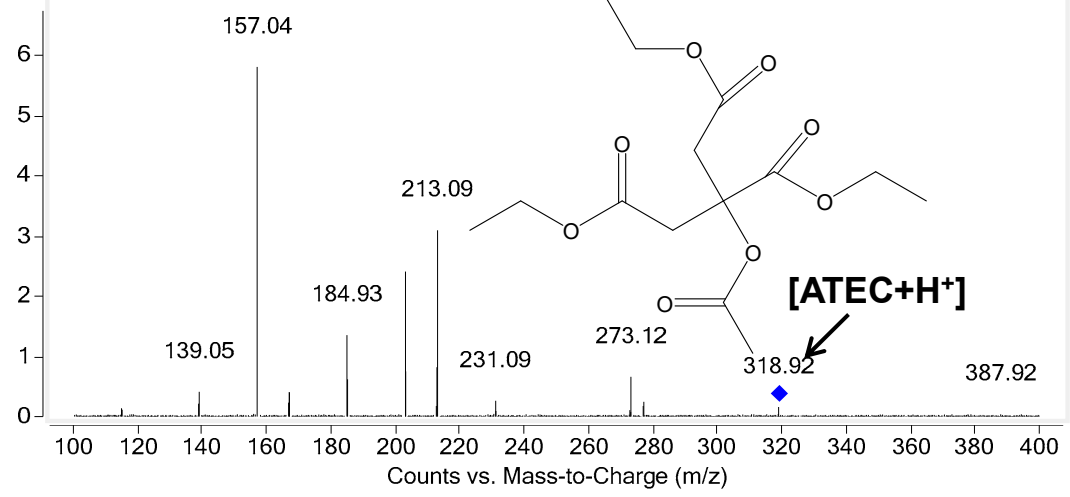

(B) $x 10^{3}$ +ESI Product lon:1 (rt: 0.098-0.260 min, 6 scans) Frag=100.0V CF=0.000 DF=0.000 CID@6.0..

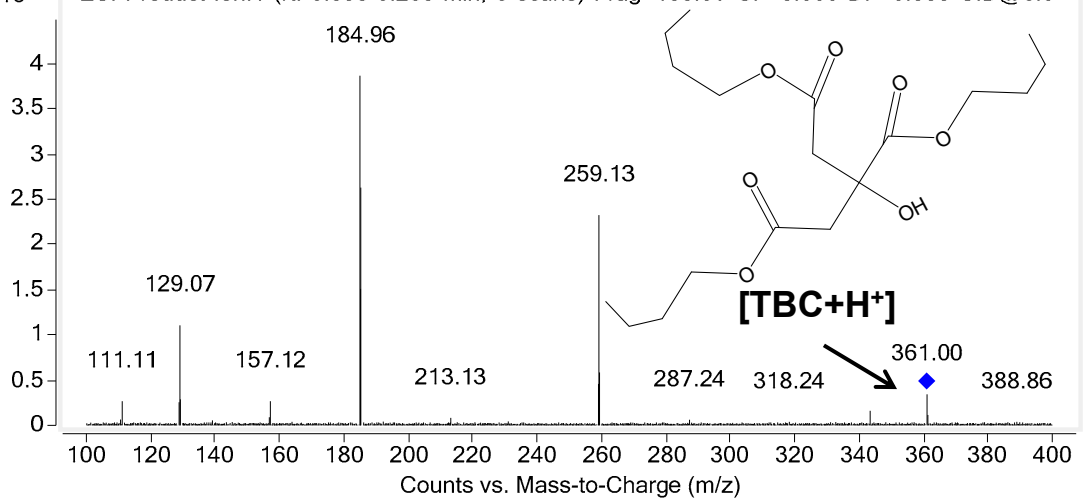

Figure 1. Product ion spectrum of (A) Acetyl triethyl citrate (ATEC) and (B) tributyl citrate internal standard (TBC IS).

\subsection{LC-QTOF MS}

For metabolite profiling, the samples were analyzed by an LC-QTOF-MS instrument consisting of an Agilent 1260 HPLC system and an Agilent6530 Accurate-Mass Q-TOF system (Agilent Technologies, Santa Clara, CA, USA). A Waters Xterra C18 column $(2.1 \mathrm{~mm} \times 150 \mathrm{~mm}, 3.5 \mu \mathrm{m})$ was used, and the mobile phase consisted of $0.1 \%$ formic acid (solvent $\mathrm{A}$ ) and $0.1 \%$ formic acid in $90 \% \mathrm{ACN}$ (solvent B). The flow rate was $0.3 \mathrm{~mL} / \mathrm{min}$. Gradient elution was performed as follows: initially, $10 \% \mathrm{~B} ; 0-15 \mathrm{~min}$, $10-50 \%$ B; $15-18 \mathrm{~min}, 50-70 \%$ B; $18-20 \mathrm{~min}, 70-90 \%$ B; $20-21 \mathrm{~min}, 90 \%$ B; $21-21.1,90-10 \%$ B; $21.1-27$, $10 \% \mathrm{~B}$. An electrospray ionization source was used, and mass detection was performed in the positive ion mode. The capillary voltage was $4.0 \mathrm{kV}$, and the fragment energy was $150 \mathrm{~V}$.

\section{Results and Discussion}

\subsection{Analytical Method Validation}

\subsubsection{Selectivity}

Representative multiple reaction monitoring chromatograms are shown in Figure 2A,B for blank plasma and plasma spiked with ATEC $(10 \mathrm{ng} / \mathrm{mL})$ and TBC $(100 \mathrm{ng} / \mathrm{mL})$. Chromatograms of the plasma samples obtained $1 \mathrm{~h}$ after i.v. and p.o. administration of ATEC to the rats are illustrated in Figure 2C,D. Sharp and fine peaks were obtained at retention times of 2.4 and $2.9 \mathrm{~min}$ for ATEC and TBC (IS), respectively. No interference was observed, indicating that the developed method was selective for the analytes in the plasma samples. 
(A)

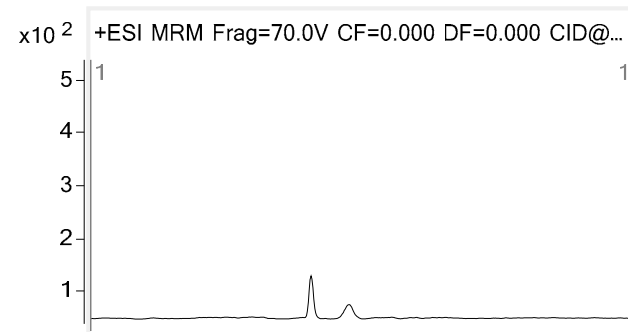

$\mathrm{x} 10^{2}+\mathrm{ESI}$ MRM Frag=104.0V CF=0.000 DF=0.000 CID...

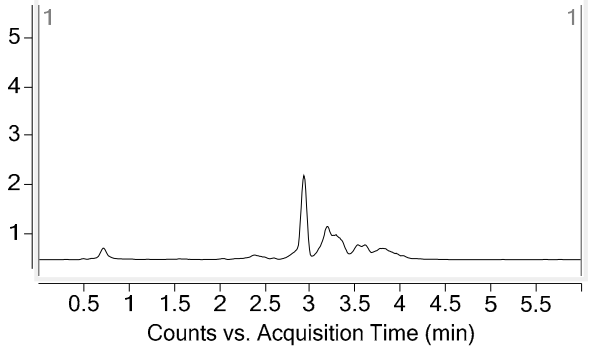

(C)

$x 10^{4}+E S I$ MRM Frag=70.0V CF=0.000 DF=0.000 CID@...

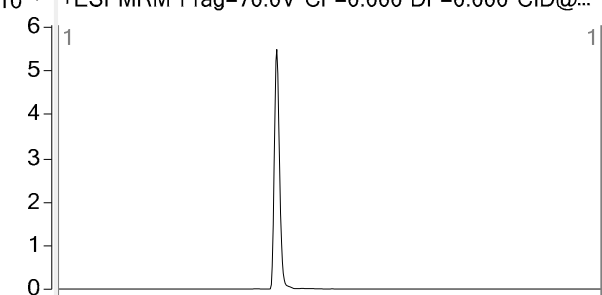

$\mathrm{x} 10^{3}+\mathrm{ESI}$ MRM Frag=104.0V CF=0.000 DF=0.000 CID.

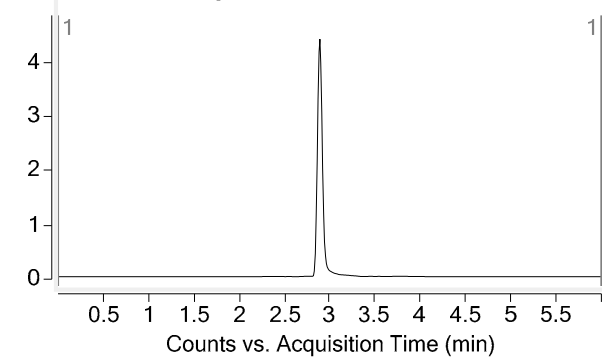

(B)

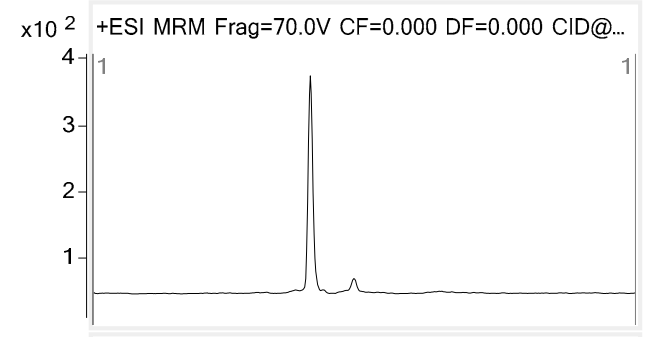

$x 10^{3}+E S I$ MRM Frag=104.0V CF=0.000 DF=0.000 CID...

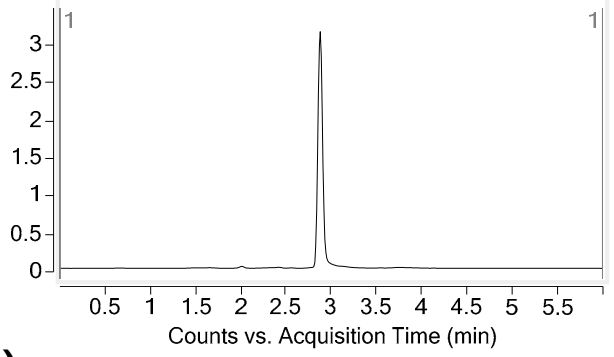

(D)

x10 4 +ESI MRM Frag=70.0V CF=0.000 DF=0.000 CID@...

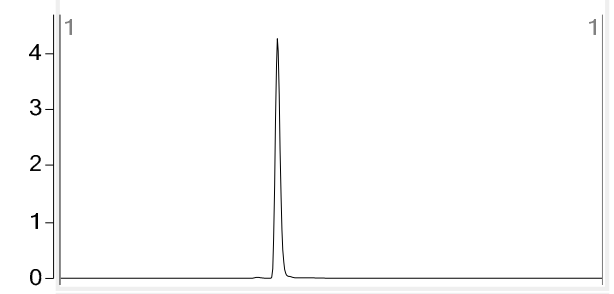

$x 10^{3}+$ ESI MRM Frag=104.0V CF=0.000 DF=0.000 CID...

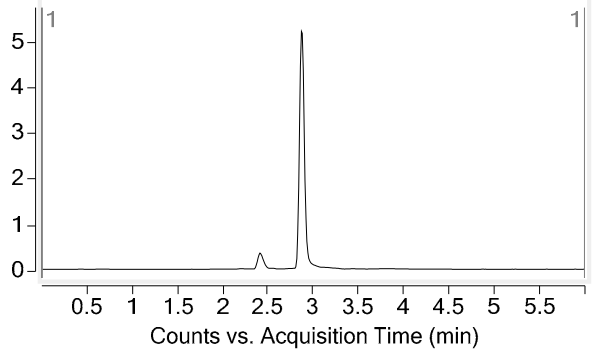

Figure 2. Typical MRM chromatograms of ATEC (top) and TBC (IS; bottom), (A) blank rat plasma, (B) blank rat plasma spiked with ATEC (10 ng/mL) and IS (100 ng/mL); rat plasma samples taken (C) 2 min after i.v. and (D) 15 min after p.o. administration of ATEC.

\subsubsection{Linearity}

Seven calibration standards (i.e., 10, 50, 100, 200, 500, 1000, and $2000 \mathrm{ng} / \mathrm{mL}$ ) of ATEC were used for construction of the plasma calibration curve. The calibration standard curves were linear and reliable over the standard concentrations across the calibration range. The regression coefficient $\left(r^{2}\right)$ was greater than 0.990 . The precision and accuracy of the calibration standard curves were reliable (less than $\pm 15 \%$ RSD) for all the tested concentrations.

\subsubsection{Precision and Accuracy}

The QC samples were assayed for intra-day and inter-day precision and accuracy at concentrations of $10,30,300$, and $1600 \mathrm{ng} / \mathrm{mL}$ (Table 1). The intra-day and inter-day accuracies were $89.1-102.9 \%$ and $94.0-99.8 \%$, respectively. Intra-day and inter-day precisions were within $8.0 \%$ and $8.2 \%$, respectively. 
Table 1. Intra- and inter-day accuracy and precision for the determination of ATEC in rat plasma. QC, Quality Control, CV, LLOQ, lower limit of quantification.

\begin{tabular}{cccccc}
\hline \multirow{2}{*}{ QC level } & \multirow{2}{*}{ Nominal (ng/mL) } & \multicolumn{2}{c}{ Intra-day $(\boldsymbol{n}=\mathbf{5})$} & \multicolumn{2}{c}{ Inter-run $(\boldsymbol{n}=3)$} \\
\cline { 3 - 5 } & & Accuracy (\%) & CV (\%) & Accuracy (\%) & CV (\%) \\
\hline LLOQ & 10 & 101.5 & 8.0 & 98.2 & 6.9 \\
Low & 30 & 102.9 & 6.8 & 98.2 & 3.3 \\
Mid & 300 & 100.7 & 4.5 & 99.8 & 2.6 \\
High & 1600 & 89.1 & 3.0 & 94.0 & 7.4 \\
\hline
\end{tabular}

\subsubsection{Extraction recovery, matrix effect, and process efficiency}

At concentrations of 50 and $1600 \mathrm{ng} / \mathrm{mL}$, the mean extraction recoveries of ATEC from rat plasma were $103.9 \pm 6.9 \%$ and $93.4 \pm 6.5 \%$, respectively, and the matrix effects were $67 \pm 4.0 \%$ and $62.9 \pm 3.2 \%$, respectively. The mean process efficiencies were $69.6 \pm 4.3 \%$ and $58.9 \pm 7.0 \%$ at concentrations of 50 and $1600 \mathrm{ng} / \mathrm{mL}$, respectively. The data indicated that ATEC was easily recovered from rat plasma after protein precipitation, and that the matrix effect was negligibly low.

\subsubsection{Stability}

The stability of ATEC was investigated in a standard stock solution and plasma samples at QC levels. The resulting data are summarized in Table 2. ATEC was stable in rat plasma samples stored at $-20^{\circ} \mathrm{C}$ for 14 days $(>90.8 \%, n=3)$, at room temperature for $8 \mathrm{~h}(>96.3 \%, n=3)$, and during three cycles of freeze and thaw at $-20{ }^{\circ} \mathrm{C}(>105.8 \%, n=3)$. The postpreparative QC samples were stable in an auto-sampler at $4^{\circ} \mathrm{C}$ for at least $12 \mathrm{~h}(n=3,>91.0 \%)$. These results indicated that ATEC was stable during all the preparation and analytical procedures.

Table 2. Stability of ATEC in rat plasma.

\begin{tabular}{|c|c|c|c|}
\hline \multirow{2}{*}{\multicolumn{2}{|c|}{ Stability Test }} & \multicolumn{2}{|c|}{ \% Recovery } \\
\hline & & \multirow{2}{*}{$\begin{array}{l}50 \mathrm{ng} / \mathrm{mL} \\
96.3 \pm 3.6\end{array}$} & \multirow{2}{*}{$\begin{array}{c}\mathbf{1 6 0 0} \mathbf{~ n g} / \mathbf{m L} \\
97.9 \pm 7.0\end{array}$} \\
\hline Short-term & (RT ${ }^{a}$ for $8 \mathrm{~h}$ ) & & \\
\hline Long-term & $\left(-20^{\circ} \mathrm{C}\right.$ for 21 day) & $90.8 \pm 6.1$ & $97.3 \pm 7.5$ \\
\hline Freeze-thaw & $\left(-20^{\circ} \mathrm{C}, 3\right.$ cycles $)$ & $105.8 \pm 8.7$ & $111.6 \pm 4.9$ \\
\hline Post-preparative & $\left(4^{\circ} \mathrm{C}\right.$ for $\left.12 \mathrm{~h}\right)$ & $95.1 \pm 4.6$ & $91.0 \pm 4.3$ \\
\hline
\end{tabular}

\subsection{Pharmacokinetic Study}

The developed method was successfully applied in a pharmacokinetic study of ATEC. We set the i.v. dose $(10 \mathrm{mg} / \mathrm{kg})$ according to the previous toxicology studies [6,7], but the oral pharmacokinetics was investigated at a higher dose $(500 \mathrm{mg} / \mathrm{kg})$, considering the detectability of ATEC. Figure 3 shows the mean plasma concentration-time profiles of ATEC following i.v. and oral administration. The plasma concentrations of ATEC rapidly decreased and were not detected after $0.5 \mathrm{~h}$ and $6 \mathrm{~h}$ following the administration of the i.v. dose of $10 \mathrm{mg} / \mathrm{kg}$ and the oral dose of $500 \mathrm{mg} / \mathrm{kg}$ of ATEC to the rats. The basic pharmacokinetic parameters of ATEC in the rats were calculated on the basis of the plasma concentration data represented in Table 3. The volume of distribution $(\mathrm{Vz})$ was $4.8 \mathrm{~L} / \mathrm{kg}$, which was higher than the volume of body water, indicating the possibility of distribution into the extra-vascular space. The absolute bioavailability (F) of ATEC was 14.8\% (as calculated by the dose-corrected AUC p.o. divided by the AUC i.v.). This relatively low $\mathrm{F}$ value pointed to poor absorption of ATEC from the gastrointestinal tract, degradation of ATEC in the gut, and extensive first-pass effects. After i.v. administration, ATEC was rapidly eliminated with a terminal half-life of 0.03 and mean residence time of $0.03 \mathrm{~h}$, whereas oral administration of ATEC resulted in $1.03 \mathrm{~h}$ of terminal half-life and a mean residence time of $6.56 \mathrm{~h}$. Longer terminal half-life and residence time were observed after oral 
administration than intravenous injection. It has been reported that this phenomenon is observed for certain drugs [21]. There could be several reasons, but one possible cause is flip-flop [21]. In this case, the absorption rate is much slower than the elimination rate, and the terminal slope is not determined by clearance and volume of distribution. Rather, bioavailability factors such as the rate and extent of absorption may control the terminal slope of the oral dose. This factor might affect the higher Vz/F value of the oral dose [22].

(A)

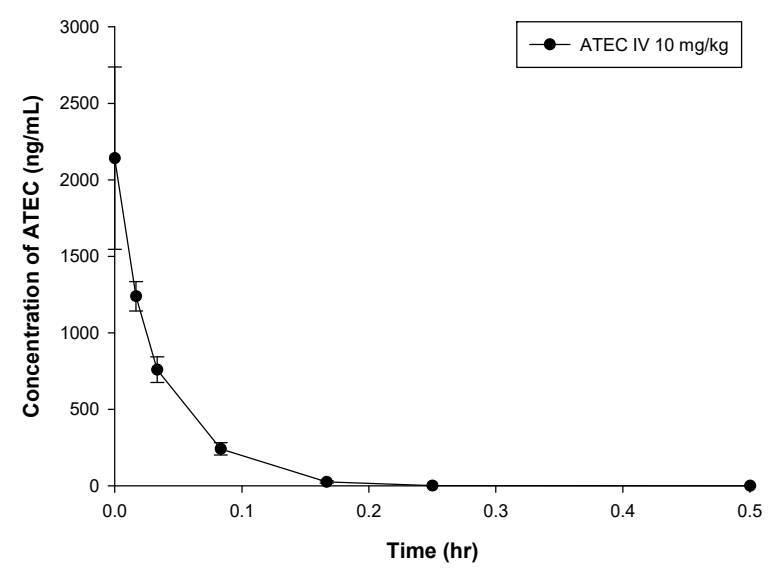

(B)

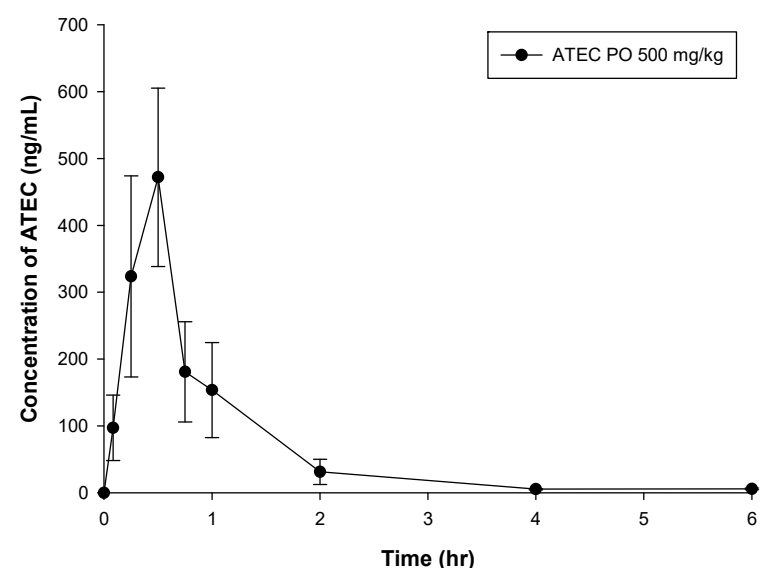

Figure 3. Mean plasma concentration-time profile of ATEC (A) after intravenous (i.v.) administration of $10 \mathrm{mg} / \mathrm{kg}$ of ATEC to rats $(n=6)$ and (B) after oral (p.o.) administration of $500 \mathrm{mg} / \mathrm{kg}(n=6)$. Data are expressed as mean \pm SD. The initial concentrations in the i.v. administration were estimated and indicated.

Table 3. Pharmacokinetic parameters after i.v. and p.o. administration of ATBC to rats.

\begin{tabular}{|c|c|c|c|c|}
\hline \multirow{2}{*}{ Parameter } & \multicolumn{2}{|c|}{ IV (10 mg/kg, $n=6)$} & \multicolumn{2}{|c|}{ PO $(500 \mathrm{mg} / \mathrm{kg}, n=6)$} \\
\hline & GM & $95 \% \mathrm{CI}$ & GM & $95 \% \mathrm{CI}$ \\
\hline AUC (ng.h/mL) & 78.1 & $64.5-95.7$ & 529.6 & $379.4-893.9$ \\
\hline$T_{\max }(\mathrm{h})^{\mathrm{a}}$ & - & - & 0.5 & $0.25-0.5$ \\
\hline$C_{\max }(\mathrm{ng} / \mathrm{mL})$ & 1219.6 & 1049.6-1427.6 & 444.5 & $271.8-834.3$ \\
\hline$T_{1 / 2}(\mathrm{~h})$ & 0.03 & $0.02-0.03$ & 1.03 & $0.75-1.46$ \\
\hline $\mathrm{Vz}(\mathrm{L} / \mathrm{kg})$ & 4.6 & $3.7-5.8$ & $215.6^{b}$ & $8.1-733.2$ \\
\hline $\mathrm{Cl}(\mathrm{L} / \mathrm{h} / \mathrm{kg})$ & 125.1 & $105.0-150.6$ & $145.5^{c}$ & $47.6-333.1$ \\
\hline $\operatorname{MRT}(\mathrm{h})$ & 0.03 & $0.03-0.04$ & 6.56 & $3.58-12.63$ \\
\hline
\end{tabular}

GM: geometric mean; CI: confidence interval; AUC: area under the curve for concentrations; $T_{\max }$ : time for peak concentration; Cmax: peak concentration; $\mathrm{T}_{1 / 2}$ : elimination half-life; $\mathrm{Cl}$ : clearance; Vz: volume of distribution; MRT: mean residence time; F: bioavailability. ${ }^{\mathrm{a}}$ represented as a median value with range. ${ }^{\mathrm{b}} \mathrm{Vz} / \mathrm{F} ;{ }^{\mathrm{c}} \mathrm{Cl} / \mathrm{F}$ 


\subsection{Metabolism Study}

To characterize the metabolism of ATEC, we tested the metabolic stability of ATEC in rat plasma and liver microsomes (Figure 4). ATEC was very stable in $\mathrm{pH} 7.4$ phosphate buffered saline. In rat plasma, ATEC was gradually metabolized, and less than $20 \%$ of the initial amount remained $60 \mathrm{~min}$ after incubation. However, ATEC was rapidly metabolized in liver microsomes and readily disappeared in $5 \mathrm{~min}$ after incubation. These data suggested that ATEC may be eliminated mainly via metabolic clearance.

(A)

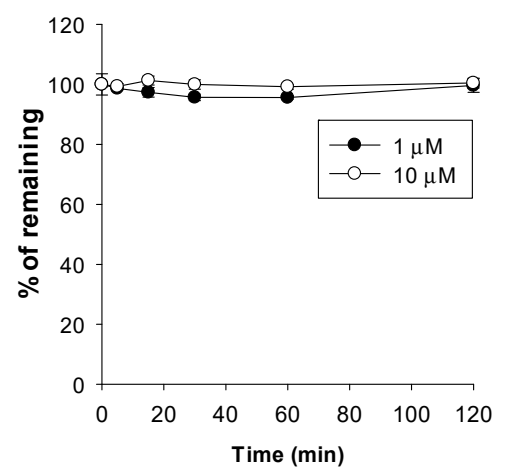

(B)

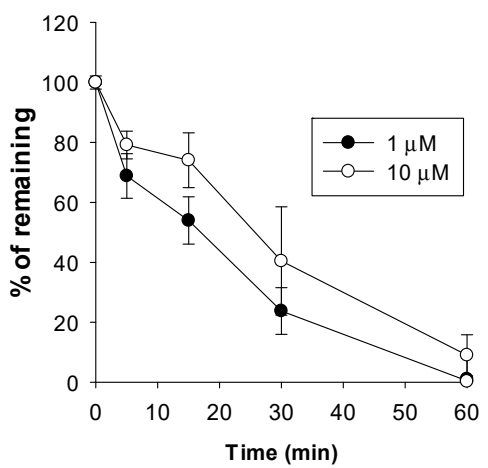

(C)

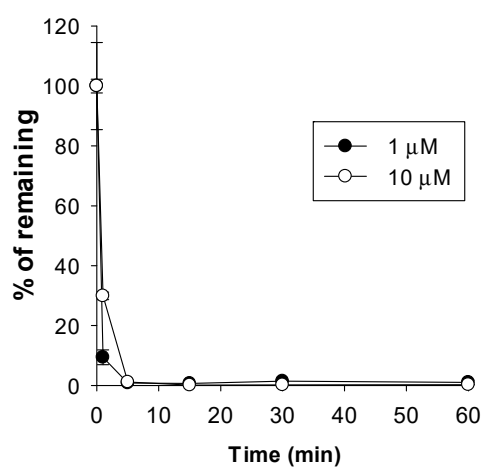

Figure 4. Metabolic stability of ATEC in (A) phosphate-buffered saline (pH 7.4), (B) rat plasma, and (C) rat liver microsomes.

Figure 5A depicts the postulated metabolic pathways of ATEC. The LC-QTOF MS analysis of plasma, urine, and feces samples showed that ATEC was extensively metabolized and excreted mainly as metabolites rather than as the parent form (Figure 5B-D). This finding was consistent with the in vitro metabolic stability data. The peaks of metabolites were postulated to correspond to acetyl diethyl citrate, diethyl citrate, and monoethyl citrate. The accurate mass data for the postulated metabolites are presented in Table 4. These data indicated that the major metabolic pathway of ATEC is via hydrolysis, mediated by esterase.

The metabolite profile according to time was plotted according to the peak area (Figure 6). Acetyl diethyl citrate and diethyl citrate were the major metabolites of ATEC. Unchanged ATEC was mostly excreted within $24 \mathrm{~h}$ after the administration of the dose, but acetyl diethyl citrate and diethyl citrate were excreted up to 4 days after the dose.

Previously, we reported the pharmacokinetic properties of ATBC that is also a citrate plasticizer and has a similar structure to that of ATEC [23]. In terms of metabolic stability, these two citrate plasticizers showed weak stability for metabolism in plasma and liver microsomes. However, ATEC was more unstable in liver microsomes than ATBC, which may result in the lower oral bioavailability of ATEC (15.9\%) compared with that of ATBC (27.4\%) [23].

Table 4. Accurate mass data for ATEC and its metabolites.

\begin{tabular}{cccccc}
\hline Name & RT & $\begin{array}{c}\text { Proposed Elemental } \\
\text { Composition [M+H]+ }\end{array}$ & Exact Mass & Measured Mass & Error (ppm) \\
\hline ATEC & 17.4 & C14H22O8 & 319.1387 & 319.1388 & -0.3 \\
Acetyl diethyl citrate & 11.5 & C12H18O8 & 291.1074 & 291.1075 & -0.3 \\
Diethyl citrate & 7.7 & C10H17O7 & 250.1047 & 250.1057 & -4.0 \\
Monoethyl citrate & 3.4 & C8H12O7 & 221.0656 & 221.0655 & 0.5 \\
\hline
\end{tabular}


(A)

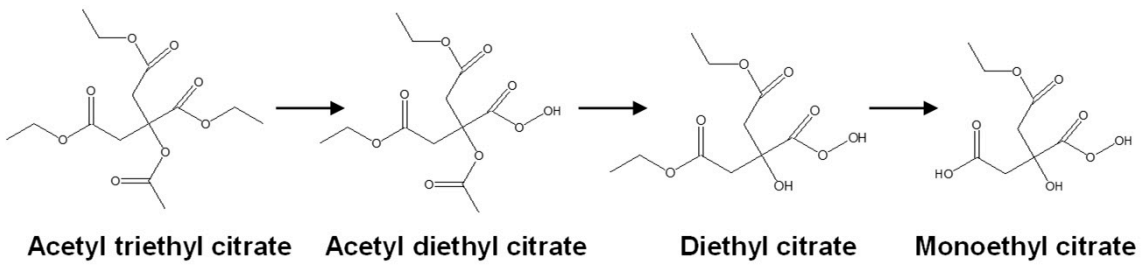

(B)

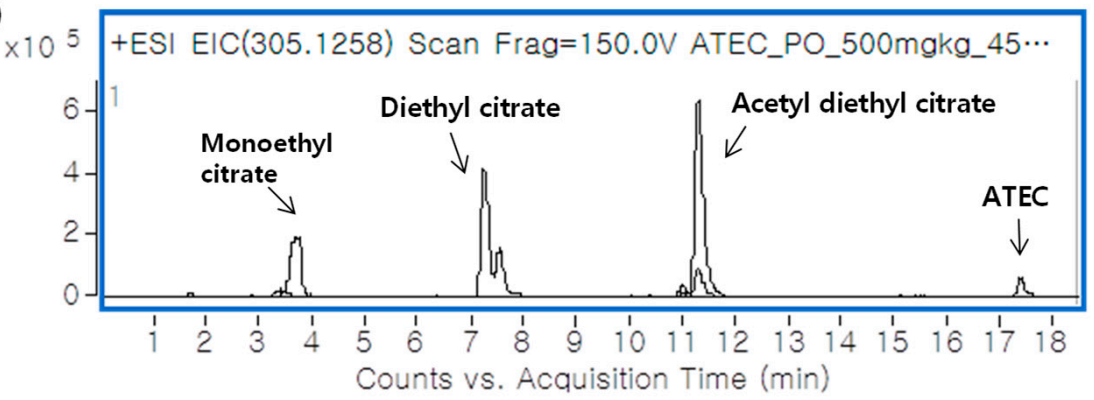

(C)

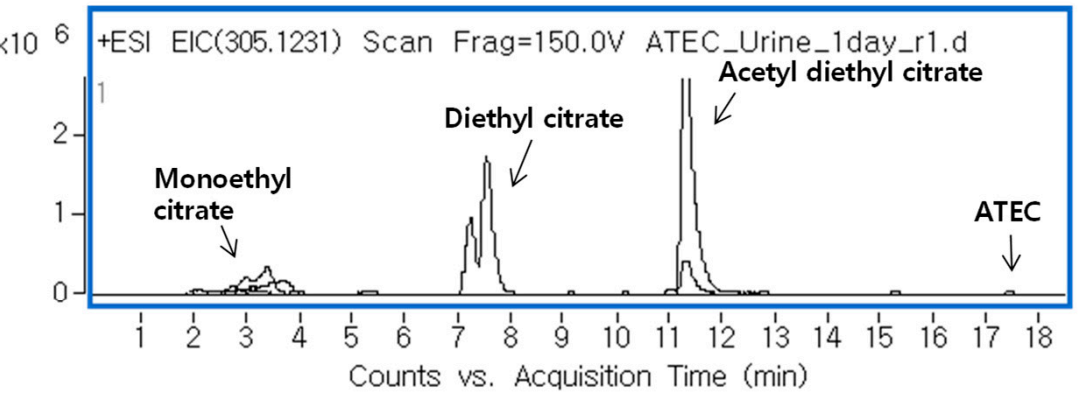

(D)

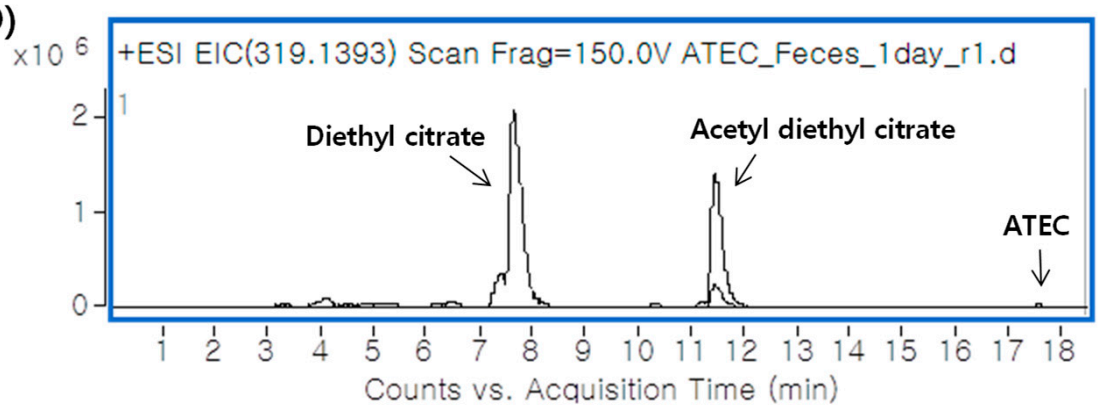

Figure 5. (A) Proposed metabolic pathway of ATEC and representative LC-MS chromatograms of (B) plasma, (C) urine, and (D) feces from rats that were orally administered ATEC. 


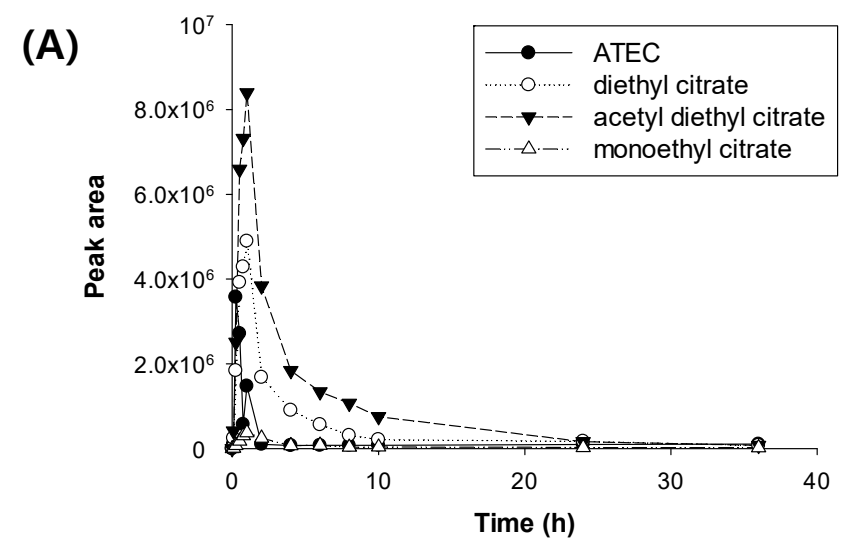

(B)
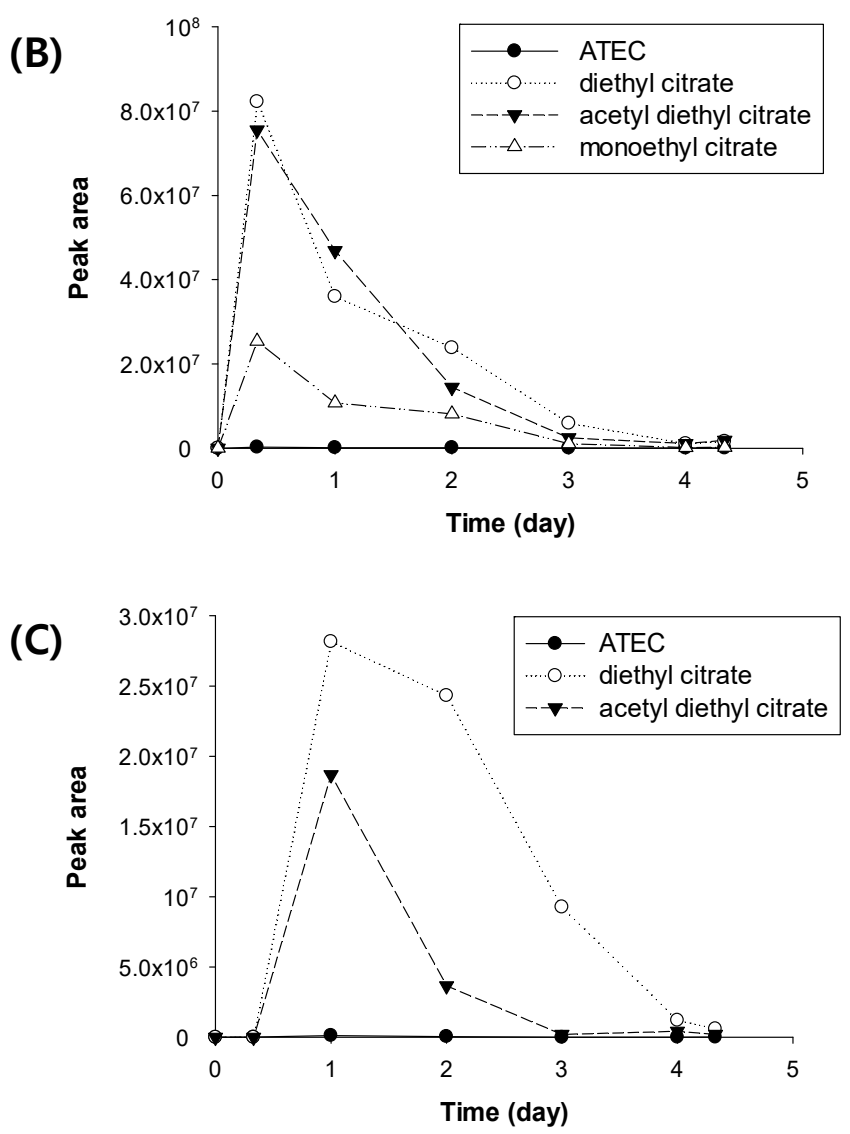

Figure 6. Plot of time-peak area for ATEC and its metabolites in (A) plasma, (B) urine, and (C) feces from the rats orally administered ATEC.

\section{Conclusions}

ATEC is used as a plasticizer in various pharmaceutical polymers. Although there have been some studies of the toxicity of ATEC, its biological properties in terms of absorption, metabolism, and excretion have not been reported. Furthermore, there have been no studies of analytical methods to determine ATEC in biological samples. In this study, we developed an accurate, sensitive, and reliable bioanalytical method for the determination of ATEC in rat plasma based on LC-MS/MS. The selectivity, linearity, precision, accuracy, and stability of the developed method were successfully validated and met established criteria. The developed method was subsequently applied to a pharmacokinetic study in rats. The pharmacokinetic study showed that ATEC rapidly disappeared from plasma. The metabolite profiling data indicated that ATEC was extensively metabolized and excreted mainly as metabolites rather than as the parent form. To our knowledge, this is the first report demonstrating 
a bioanalytical method for the determination of ATEC in biological samples and its pharmacokinetic properties. The resulting pharmacokinetic data can aid the understanding of the safety and toxicity of ATEC.

Author Contributions: Contributed to the research design: H.H.Y., M.C.G.; Conducted experiments: H.K., Y.S.J.; Contributed to data analysis and interpretation: H.K., M.S.C.; Contributed to the preparation of the manuscript: H.K., S.U.R., H.H.Y.

Funding: This research was supported by the National Research Foundation of Korea funded by the Korea government (NRF-2015M3C8A6A06012996 and NRF-2017R1A2B4001814).

Conflicts of Interest: The authors declare no conflict of interest.

\section{References}

1. Snejdrova, E.; Dittrich, M. Pharmaceutically used plasticizers. In Recent Advances in Plasticizers; Mohammad, L., Ed.; IntechOpen: Rijeka, Croatia, 2012; pp. 45-68.

2. Siepmann, J.; Lecomte, F.; Bodmeier, R. Diffusion-controlled drug delivery systems: Calculation of the required composition to achieve desired release profiles. J. Control. Release 1999, 60, 379-389. [CrossRef]

3. Fukui, E.; Miyamura, N.; Yoneyama, T.; Kobayashi, M. Drug release from and mechanical properties of press-coated tablets with hydroxypropylmethylcellulose acetate succinate and plasticizers in the outer shell. Int. J. Pharm. 2001, 217, 33-43. [CrossRef]

4. Goole, J.; Deleuze, P.; Vanderbist, F.; Amighi, K. New levodopa sustained-release floating minitablets coated with insoluble acrylic polymer. Eur. J. Pharm. Biopharm. 2008, 68, 310-318. [CrossRef] [PubMed]

5. Fadda, H.M.; Khanna, M.; Santos, J.C.; Osman, D.; Gaisford, S.; Basit, A.W. The use of dynamic mechanical analysis (DMA) to evaluate plasticization of acrylic polymer films under simulated gastrointestinal conditions. Eur. J. Pharm. Biopharm. 2010, 76, 493-497. [CrossRef] [PubMed]

6. Finkelstein, M.; Gold, H. Toxicology of the citric acid esters: Tributyl citrate, acetyl tributyl citrate, triethyl citrate, and acetyl triethyl citrate. Toxicol. Appl. Pharmacol. 1959, 1, 283-1298. [CrossRef]

7. Johnson, W., Jr. Final report on the safety assessment of acetyl triethyl citrate, acetyl tributyl citrate, acetyl trihexyl citrate, and acetyl trioctyl citrate. Int. J. Toxicol. 2002, 21, 1-17. [PubMed]

8. Xu, Y.; Gye, M.C. Developmental toxicity of dibutyl phthalate and citrate ester plasticizers in Xenopus laevis embryos. Chemosphere 2018, 204, 523-534. [CrossRef] [PubMed]

9. Kim, H.S.; Cheon, Y.P.; Lee, S.H. Hershberger Assays for Di-2-ethylhexyl Phthalate and Its Substitute Candidates. Dev. Reprod. 2018, 22, 19-27. [CrossRef] [PubMed]

10. Park, J.; Park, C.; Gye, M.C.; Lee, Y. Assessment of endocrine-disrupting activities of alternative chemicals for bis(2-ethylhexyl)phthalate. Environ. Res. 2019, 172, 10-17. [CrossRef] [PubMed]

11. Takeshita, A.; Igarashi-Migitaka, J.; Nishiyama, K.; Takahashi, H.; Takeuchi, Y.; Koibuchi, N. Acetyl Tributyl Citrate, the Most Widely Used Phthalate Substitute Plasticizer, Induces Cytochrome P450 3A through Steroid and Xenobiotic Receptor. Toxicol. Sci. 2011, 123, 460-470. [CrossRef] [PubMed]

12. Lide, D.R.; Milne, G.W.A. CRC Handbook of Data on Organic Compounds, 3rd ed.; CRC Press: Boca Raton, FL, USA, 1993.

13. Pfannhauser, W.; Eberhardt, R.; Woidich, H. Aroma analysis in food chemistry by GC/MS techniques: Determination of natural and artificial coconut flavor. Microchim. Acta 1982, 77, 159-167. [CrossRef]

14. Thoma, K.; Heckenmuller, H. Thin layer chromatographic detection of emollients in gastric juice-resistant coatings. 2. The pharmaceutic technology and analysis of gastric juice-resistant dosage forms. Pharmazie 1986, 41, 328-332. [PubMed]

15. Gutierrez-Rocca, J.C.; McGinity, J.W. Influence of water soluble and insoluble plasticizers on the physical and mechanical properties of acrylic resin copolymers. Int. J. Pharm. 1994, 103, 293-301. [CrossRef]

16. Christia, C.; Poma, G.; Harrad, S.; de Wit, C.A.; Sjostrom, Y.; Leonards, P.; Lamoree, M.; Covaci, A. Occurrence of legacy and alternative plasticizers in indoor dust from various EU countries and implications for human exposure via dust ingestion and dermal absorption. Environ. Res. 2019, 171, 204-212. [CrossRef] [PubMed]

17. Bodmeier, R.; Paeratakul, O. Determination of Plasticizers Commonly Used in Pharmaceutical Dosage Forms by High Performance Liquid Chromatography. J. Liq. Chromatogr. 1991, 14, 365-375. [CrossRef] 
18. Food and Drug Administration. Guidance for Industry: Bioanalytical Method Validation. 2018. Available online: https://www.fda.gov/downloads/Drugs/Guidances/ucm070107.pdf (accessed on 18 February 2019).

19. Rehman, S.U.; Kim, I.S.; Choi, M.S.; Luo, Z.; Yao, G.; Xue, Y.; Zhang, Y.; Yoo, H.H. Evaluation of Metabolic stability of kinsenoside, an antidiabetic candidate, in rat and human liver microsomes. Mass Spectrom. Lett. 2015, 6, 48-51. [CrossRef]

20. Park, J.S.; Rehman, S.U.; Kim, I.S.; Choi, M.S.; Lee, J.S.; In, S.; Yoo, H.H. Tentative identification of in vitro metabolites of 5-APDB, a synthetic benzofuran, by LC-Q/TOF-MS. J. Chromatogr. B 2016, 1033, 296-300. [CrossRef] [PubMed]

21. Toutain, P.L.; Bousquet-Mélou, A. Plasma terminal half-life. J. Vet. Pharmacol. Ther. 2004, 27, 427-439. [CrossRef] [PubMed]

22. Toutain, P.L.; Bousquet-Mélou, A. Volumes of distribution. J. Vet. Pharmacol. Ther. 2004, 27, 441-453. [CrossRef] [PubMed]

23. Kim, H.; Choi, M.S.; Ji, Y.S.; Kim, I.S.; Kim, G.B.; Bae, I.Y.; Gye, M.C.; Yoo, H.H. Pharmacokinetic Properties of Acetyl Tributyl Citrate, a Pharmaceutical Excipient. Pharmaceutics 2018, 10, 177. [CrossRef] [PubMed]

(C) 2019 by the authors. Licensee MDPI, Basel, Switzerland. This article is an open access article distributed under the terms and conditions of the Creative Commons Attribution (CC BY) license (http://creativecommons.org/licenses/by/4.0/). 